\title{
Assessment of Maternal and Fetal Outcomes According to Induction Methods Following Negative Oxytocin Challenge Test
}

Okan Aytekin ( $\square$ okanaytekin13@hotmail.com )

Ankara City Hospital: Ankara Sehir Hastanesi https://orcid.org/0000-0002-6430-4607

Sezin Erturk Aksakal

Mehmet Metin Altay

\section{Research Article}

Keywords: fetal outcomes, labor induction, oxytocin challenge test, maternal outcomes

Posted Date: January 6th, 2022

DOI: https://doi.org/10.21203/rs.3.rs-1232960/v1

License: (c) (1) This work is licensed under a Creative Commons Attribution 4.0 International License.

Read Full License 


\section{Abstract}

Purpose: To evaluate maternal and perinatal outcomes in high-risk patients who had negative OCTs and to investigate the effects of methods of induction on the development of fetal distress.

Methods: The hospital records of patients were reviewed retrospectively. Clinical data were obtained from medical records.

Results: OCT was performed in 551 patients and was negative in 447 patients. Among patients with a negative OCT, labor induction was preferred in 427 (95.5\%) patients. When fetal distress development was assessed according to the induction method used following a negative OCT, and fetal distress developed in $9.1 \%$ of 427 patients who underwent labor induction.

Conclusion: When outcomes were considered in pregnant women with a negative OCT, it was observed that there were no fetal deaths and a limited number of newborns with low Apgar scores. Further randomized studies are needed to draw definitive conclusions.

\section{Introduction}

Detection of fetal hypoxia during labour to minimize fetal death and neurologic sequelae related to fetal asphyxia is highly important. Electronic fetal monitorization (non-stress test [NST]), contraction stress test (CST), fetal biophysics profile, amniotic fluid index, Doppler sonography, fetal scalp blood testing, umbilical cord blood gas analysis, and neonatal Apgar scores are commonly used parameters in the assessment of intrauterine fetal state and distress [1-9]. The oxytocin challenge test (OCT) is one of the methods of the CST and commonly used for the monitorization of the fetus during the antepartum period. OCT is a test used to evaluate fetal well-being based on uterine contractions in suspected placental insufficiency. The negative OCT test was defined as the presence of accelerations in fetal heart rate, normal variability, and absence of slowdown in uterine contractions[10]. Freeman et al. used the CST for follow-up in 679 post-term cases and observed no perinatal mortality [11]. In other studies, it was shown that the perinatal mortality rate was lower than $0.1 \%$ during follow-up within the first week following a negative CST [12-15].

Delivery is induced due to maternal (preeclampsia, cardiac or renal disease), fetal (intrauterine growth retardation), or combined causes (uncontrolled diabetes mellitus, premature rupture of membrane or postterm pregnancy) [16]. There are several methods of induction. However, no method has been shown to be superior to others [17].

The aim of our study was to evaluate maternal and perinatal outcomes in high-risk patients who had negative OCTs. The secondary aim was to investigate the effects of methods of induction on the development of fetal distress.

\section{Materials And Methods}


The hospital records of patients hospitalized in the perinatal intensive care unit due to high-risk pregnancies between January 2016 and December 2016 were reviewed retrospectively. This study was approved by the institutional review board (Approval No.: 22.02.2017/02).

\section{Patient Selection}

Patients who had $\geq 34$ weeks of gestation, singleton pregnancy with vertex presentation and a negative OCT result were included in the study. Patients who had a history of cesarean delivery, uterine surgery, patients with suspected cephalopelvic disproportion, inconclusive and hyper-stimulated or suspected OCT results and a fetus with major congenital anomalies were excluded.

The following definitions were used when assessing risk factors:

- Oligohydramnios was defined as amnion fluid index $<50 \mathrm{~mm}$,

- Polyhydramnios was defined as deepest vertical pocket $>80 \mathrm{~mm}$,

- The decreased fetal movement was defined as experiencing fewer or no fetal movements by mother,

- Intrauterine growth retardation was defined as estimated fetal weight <3rd percentile according to the gestational week or confirmation by birth weight,

- Non-reactive NST was defined as lacking fetal heart rate acceleration at a 40-min period in NST monitoring,

- Preterm pregnancy was defined as gestational age between $34-36$ 6/7 weeks,

- Term pregnancy was defined as gestational age between $37-40$ 6/7 weeks,

- Post-term pregnancy was defined as gestational age $\geq 41$ weeks,

- Gestational diabetes mellitus (GDM) was defined as the presence of elevation in at least two values by $100 \mathrm{~g}$ glucose and in at least one value by $75 \mathrm{~g}$ glucose in oral glucose tolerance test,

- Preeclampsia was defined as arterial blood pressure $>140 / 90 \mathrm{~mm} \mathrm{Hg}$ and the presence of at least one of the following: proteinuria, thrombocytopenia, hepatic dysfunction, pulmonary oedema or cerebral and visual symptoms [18].

\section{Oxytocin Challenge Test}

In the OCT, ten units of oxytocin in 500 millilitres $(\mathrm{mL})$ of normal saline was given at a rate of $15 \mathrm{~mL} /$ hour using an infusion pump. The dose was doubled at 20-minute $(\mathrm{min})$ intervals until achieving three uterine contractions with sufficient intensity in a 10-min period. The OCT was considered as negative in patients who showed three uterine contractions with moderate intensity lasting 40-60 seconds but not late deceleration [19].

\section{Labour Induction Methods}

In our clinic, oxytocin (SYNPITAN®, DEVA, Turkey), Dinoproston (PROPESS Ovul®, FERRING, Switzerland), transcervical balloon catheter (COOK® Cervical Ripening Balloon, Cook Medical, Ireland) 
and Foley balloon catheter (Latex Foley Catheter®, Weel Lead Medical, China ) were used for inducing labour. Ten units of oxytocin (SYNPITAN®) in $500 \mathrm{~mL}$ normal saline was given at a rate of $15 \mathrm{~mL} / \mathrm{h}$ using an infusion pump; the dose was doubled at 20-min intervals until achieving three uterine contractions with sufficient intensity in a 10-min period. Dinoprostone was given via a slow-release vaginal delivery system (PROPESS Ovule ${ }^{\circledR}$ ). It was removed in patients who achieved active labour, those with membrane rupture and those who failed to induce labour within 12 hours. A transcervical balloon catheter and a Foley balloon catheter were administered through the cervix, as shown in studies in the extra-amniotic region $[20,21]$.

The patient's gestational age, gravidity, parity and body mass index (BMI), risk factors leading to the OCT, labour induction methods used following a negative OCT, time from negative OCT to delivery, mode of delivery, and indications for cesarean section were recorded. In addition, data regarding fetal sex, birth weight, birth height, labour complications, Apgar scores at minutes 1 and 5, admission to neonatal intensive care unit (NICU), indications for NICU admission, length of NICU stay, and stillbirth were also recorded.

\section{Statistical Analysis}

All statistical analyses were performed using the Statistical Package for the Social Sciences (SPSS) for Windows version 22.0. Descriptive values are expressed as arithmetic mean \pm standard deviation, median and percent. The Chi-square test was used to analyze independent quantitative data, and Fisher's exact test was used when terms for the Chi-square test were inappropriate. A p value $<0.05$ was considered as statistically significant.

\section{Results}

It was found that the OCT was performed in 551 patients between January 2016 and December 2016. It was seen that OCT was negative in $447(81.1 \%)$ patients, positive in 50 patients $(9.1 \%)$, and inconclusive in $54(9.8 \%)$ patients. It was found that the mean maternal age was $25.7 \pm 5.1$ years, and the mean gestational age was $39.2 \pm 1.5$ weeks. The mean gravidity was $1.8 \pm 1.1$, and the mean BMI was $29.1 \pm$ $4.2 \mathrm{~kg} / \mathrm{m}^{2}$ in 447 patients with a negative OCT.

When the induction methods used were assessed, it was seen that labour induction was preferred in 427 (95.5\%) patients, and spontaneous delivery occurred in 20 patients (4.5\%) among patients with a negative OCT. In addition, it was found that labour induction was performed using dinoprostone in 237 (53\%) patients, oxytocin alone in $117(26.2 \%)$ patients, Cook balloon catheter with oxytocin inductions in $47(10.5 \%)$ patients, and Foley balloon catheter with oxytocin inductions in 26 (5.8\%) patients (Table 1).

Of the patients, 310 (72.6\%) gave birth via vaginal delivery (VD) and 117 (27.4\%) via cesarean section $(\mathrm{C} / \mathrm{S})$. When indications for $\mathrm{C} / \mathrm{S}$ were assessed, it was found that $\mathrm{C} / \mathrm{S}$ was performed due to fetal distress 
in 39 (33.3\%) patients, non-progressive labour in 74 (63.2\%) patients, placental detachment in two (1.7\%) patients, umbilical cord prolapse in one $(0.9 \%)$ patient, and risk for chorioamnionitis in one $(0.9 \%)$ patient (Table 2).

When the causes of fetal distress following OCT were assessed according to risk factors prompting OCT, it was seen that $\mathrm{C} / \mathrm{S}$ was performed in $10(5 \%)$ patients who underwent OCT due to oligohydramnios, comprising $25.6 \%$ of all cases with fetal distress, followed by six (15.4\%) patients with post-term pregnancy plus oligohydramnios, and six $(15.4 \%)$ patients with post-term pregnancy alone. A significant difference was detected in oligohydramnios, preeclampsia, polyhydramnios and gestational cholestasis between groups with or without fetal distress when they were assessed according to risk factors prompting OCT (Table 3).

When fetal distress development was assessed according to the induction method used following a negative OCT, it was seen that fetal distress developed in $25.0 \%$ of 20 patients $(n=5)$ who did not undergo labour induction, and $9.1 \%$ of 427 patients $(n=39)$ who underwent labour induction (Table 4$)$. No significant difference was detected in fetal distress development according to the use of labour induction. When the induction methods used were assessed, it was seen that the dinoprostone group $(n=237)$ had the highest rate of fetal distress development (10.5\%). No significant difference was detected in fetal distress development according to induction method used ( $p>0.05$; Table 4).

\section{Perinatal Outcomes}

When NICU admission and its indications were assessed, it was seen that 397 neonates (93\%) did not require NICU admission. Of the neonates who required NICU admission, it was found that $53.3 \%(n=16)$ were admitted due to neonatal respiratory distress, 33.3\% $(n=10)$ due to neonatal jaundice, $10 \%$ due to prematurity, one (3.3\%) due to brachial plexus injury (Table 5).

Perinatal outcomes were assessed by stratifying according to gestational age; $\geq 41$ weeks and between $\geq 37$ and $<41$ weeks. It was found that of the 311 newborns with gestational age between $\geq 37$ and $<41$ weeks, $46.9 \%$ were boys, and $53.1 \%$ were girls. It was found that the mean birth weight was $3011 \pm 383 \mathrm{~g}$ and the mean birth length was $49.2 \pm 2.4 \mathrm{~cm}$. The median Apgar scores were 9 and 10 at minutes 1 and 5 , respectively. Again, It was found that of the 108 newborns with gestational age $\geq 41$ weeks, $45.4 \%$ were boys, and $54.6 \%$ were girls. The mean birth weight was $3394 \pm 349 \mathrm{~g}$ and mean birth length was $51.2 \pm$ $1.5 \mathrm{~cm}$. The median Apgar scores were 9 and 10 at minutes 1 and 5, respectively. It was seen that 31 newborns required NICU admission, including six newborns with gestational age $<37$ weeks. Prematurity was the underlying cause of NICU admission in $50 \%$ of six newborns with gestational age $<37$ weeks. In the remaining 25 newborns with gestational age $\geq 37$ weeks, respiratory distress was the underlying cause of NICU admission in $45.1 \%$ (Table 6).

When the relationship between the time from OCT to delivery and fetal distress was assessed, fetal distress development was detected after OCT in 39 newborns. Of these 39 newborns, fetal distress developed within the first 24 hours in 24 (10.4\%) and between hours 24 and 72 in 15 (8.2\%). No fetal 
distress development was detected beyond 72 hours after the OCT $(p=0.388)$. When Apgar scores were assessed in infants born following a negative OCT, it was found that Apgar scores were $<7$ at minute 1 in 10 newborns and four newborns at minute 5 . When the relationship between the time from the OCT to delivery and Apgar scores was assessed, it was seen that there was no significant difference between Apgar scores $<7$ and $>7(p=0.416)$ (Table 7).

\section{Discussion}

This descriptive study investigated perinatal outcomes in pregnant women with a negative OCT. It was found that labour was induced in $95 \%$ of pregnant women with a negative OCT, dinoprostone and oxytocin were the most commonly used methods of labour induction, and delivery was via vaginal delivery in $72.6 \%$ and via C/S in $27.4 \%$. No significant difference was detected in fetal distress rates between patients who did and did not undergo labour induction. In addition, there was no significant difference in fetal distress rates across the induction methods used. Of the patients, $7 \%$ were admitted to the NICU, most commonly due to respiratory distress and jaundice. No significant relationship was detected between fetal distress development, time from the OCT to delivery, and Apgar scores at minute 5 .

In our study, delivery was via C/S in 117 (27.4\%) patients. When C/S indications were assessed, fetal distress was the most common indication (33.3\%). In the study of Waledziak et al., 69 (33.8\%) of 204 patients with negative OCT underwent $\mathrm{C} / \mathrm{S}$. The authors found that abnormal heart traces comprised $37.6 \%$ of $\mathrm{C} / \mathrm{S}$ indications [10]. The $\mathrm{C} / \mathrm{S}$ rate in our study was in agreement with study as mentioned above.

In our study, fetal distress findings during follow-up and labour were observed in 39 (9.1\%) of 427 pregnant women who were followed after a negative OCT. This rate indicated that OCT was not effective in predicting fetal distress during labour. In a study by Barry et al., fetal distress findings during labour were observed in three (3\%) of 101 patients with a negative OCT [22]. The difference may be attributed to the difference in sample sizes. Again, Apgar scores at minute 1 were $<7$ in 10 of 100 newborns, three of which had Apgar scores at minute $5<7$ (3\%). In our study, Apgar scores at minute 1 were $<7$ in 10 of 427 patients, four of whom had Apgar scores at min 5 of $<7(0.9 \%)$. In a study by Bernard et al., fetal distress

findings during labour were observed in five of 97 patients with a negative OCT [23]. The authors provided no data regarding Apgar scores, diagnoses, and labour induction methods.

Our study used labour induction methods in 427 of 447 patients with a negative OCT, and fetal distress were observed in $9.1 \%$. No significant difference was found in fetal distress development across the induction methods ( $p>0.05)$. In a study by Hendrik et al., labour was induced in 7683 nulliparous pregnant women and fetal distress findings were observed in $2.6 \%$ of patients [24]. However, the study had some limitations including the selection of low-risk pregnancies, excluding post-term and low-birth-weight pregnancies, and a lack of data regarding fetal well-being before induction. In a study by Anjel et al., labour was induced in 429 low-risk, nulliparous pregnant women and fetal distress findings were 
observed in $5.1 \%$ of patients. The authors assigned patients into two groups: labour was directly induced using oxytocin in 286 patients and using oxytocin following cervical preparation with a Foley balloon catheter in 143 patients. The fetal distress rate was 7\% among patients who underwent cervical preparation with a Foley balloon catheter and $4.2 \%$ in the oxytocin group [25]. Again, the study was conducted on low-risk term pregnant women and no test was performed to assess fetal well-being before induction. In our study, the fetal distress rate was $7.7 \%$ in the Foley balloon catheter and oxytocin group and $9.4 \%$ in the oxytocin group. Again, in this study, like other studies, it was applied to term pregnant women with low risk and no test was applied for fetal well-being before induction. However, our study was limited by the small number of patients in the Cook balloon catheter and Foley balloon catheter groups and patients who did not undergo labour induction.

During follow-up from OCT to delivery, no stillbirths were observed in 427 pregnant women with a negative OCT. In a study by Larry et al., seven cases of stillbirth (1\%) were observed during a one-week follow-up among 680 pregnant women with a negative OCT [26]. The authors reported that causes of stillbirth included cord injury in three cases, placental detachment in one case, multiple anomalies in one case, and undefined in two cases, suggesting that fetal deaths were not due to disruption of fetal wellbeing. In a study on 1337 high-risk pregnant women, Nageotte et al. reported only one fetal death within seven days following a negative CST [27]. Again, in a study on 679 women who underwent CST due to post-term pregnancy, no fetal death was observed by Freeman et al. [11]. In another study, CST was used to assess fetal well-being in 337 pregnant women with a previous history of stillbirth and no fetal deaths were observed [12].

Our study has some strengths. In studies about outcomes after negative OCT, fetal mortality rates were investigated during one-week follow-up in general [11, 12, 26, 27]. However, we evaluated fetal distress and Apgar scores in addition to fetal mortality. Low-risk pregnancies were preferred in studies that investigated outcomes according to induction methods, and no data were provided regarding fetal wellbeing before induction $[24,25]$.

Our study also has limitations. The fact that all groups underwent induction, including high-risk patients, limited the ability to determine whether disruption in fetal well-being was caused by the risk status of patients or the induction method used.

When outcomes were considered in pregnant women with a negative OCT, it was observed that there were no fetal deaths and a limited number of newborns with low Apgar scores. It could be suggested that OCT is an effective method to predict fetal well-being but may not provide data regarding fetal distress development during labour. Further randomized studies are needed to draw definitive conclusions.

\section{Declarations}

\section{Statements and Declarations}


The authors declare that no funds, grants, or other support were received during the preparation of this manuscript. The authors have no relevant financial or non-financial interests to disclose.

\section{Author Contribution}

Aytekin O: Project development, Data Collection, Manuscript writing

Aksakal SE: Data analysis, Manuscript editing

Altay MM: Project development, Manuscript editing

\section{Ethics Approval}

This is an observational study. The Etlik Zubeyde Woman Hospital Research Ethics Committee has confirmed that no ethical approval is required.

\section{Conflict of Interest}

The authors declare that they have no conflict of interest.

\section{References}

1. Boylan P. 5 Intrapartum fetal monitoring. Bailliere's clinical obstetrics and gynaecology. 1987;1(1):7395.

2. Apgar V. A proposal for a new method of evaluation of the newborn. Classic Papers in Critical Care. 1952;32(449):97.

3. Aarnoudse J, Huisjes H, Gordon H, Oeseburg B, Zijlstra W. Fetal subcutaneous scalp PO2 and abnormal heart rate during labor. American journal of obstetrics and gynecology. 1985;153(5):565-6.

4. Fields L, Entman S, Boehm F. Correlation of the one-minute Apgar score and the pH value of umbilical arterial blood. Southern medical journal. 1983;76(12):1477-9.

5. Gilstrap III LC, Leveno KJ, Burris J, Williams ML, Little BB. Diagnosis of birth asphyxia on the basis of fetal $\mathrm{pH}$, Apgar score, and newborn cerebral dysfunction. American journal of obstetrics and gynecology. 1989;161(3):825-30.

6. Holtzman RB, Banzhaf WC, Silver RK, Hageman JR. Perinatal management of meconium staining of the amniotic fluid. Clinics in perinatology. 1989;16(4):825-38.

7. Riley RJ, Johnson J. Collecting and analyzing cord blood gases. Clinical obstetrics and gynecology. 1993;36(1):13-23. 
8. Sarnat HB, Sarnat MS. Neonatal encephalopathy following fetal distress: a clinical and electroencephalographic study. Archives of neurology. 1976;33(10):696-705.

9. Vintzileos AM, Gaffney SE, Salinger LM, Kontopoulos VG, Campbell WA, Nochimson DJ. The relationships among the fetal biophysical profile, umbilical cord $\mathrm{pH}$, and Apgar scores. American journal of obstetrics and gynecology. 1987;157(3):627-31.

10. Różańska-Walędziak A, Czajkowski K, Walędziak M, Teliga-Czajkowska J. The Present Utility of the Oxytocin Challenge Test-A Single-Center Study. Journal of clinical medicine. 2020;9(1):131.

11. Freeman RK, Garite TJ, Modanlou H, Dorchester W, Rommal C, Devaney M. Postdate pregnancy: utilization of contraction stress testing for primary fetal surveillance. American journal of obstetrics and gynecology. 1981;140(2):128-35.

12. Freeman RK, Dorchester W, Anderson G, Garite TJ. The significance of a previous stillbirth. American journal of obstetrics and gynecology. 1985;151(1):7-13.

13. Druzin M, Karver M, Wagner W, Hutson J, Waltner A, Kogut E. Prospective evaluation of the contraction stress and nonstress tests in the management of post-term pregnancy. Surgery, gynecology \& obstetrics. 1992;174(6):507-12.

14. Gabbe SG, Mestman JH, Freeman RK, Anderson GV, Lowensohn RI. Management and outcome of class A diabetes mellitus. American journal of obstetrics and gynecology. 1977;127(5):465-9.

15. Lagrew DC, Pircon RA, Towers CV, Dorchester W, Freeman RK. Antepartum fetal surveillance in patients with diabetes: when to start? American journal of obstetrics and gynecology. 1993;168(6):18206.

16. Obstetricians ACo, Gynecologists. ACOG practice bulletin no. 107: induction of labor. Obstet Gynecol. 2009;114:386-97.

17. Alfirevic Z, Keeney E, Dowswell T, Welton NJ, Medley N, Dias S, et al. Which method is best for the induction of labour? A systematic review, network meta-analysis and cost-effectiveness analysis. Health technology assessment. 2016;20(65):1-583.

18. Gabbe S, Jennifer R, Simpson J. Obstetrics: normal and problem pregnancies. Philadelphia. Elsevier/Saunders; 2012.

19. Freeman RK. The use of the oxytocin challenge test for antepartum clinical evaluation of uteroplacental respiratory function. American journal of obstetrics and gynecology. 1975;121(4):481-9.

20. Hadi H. Cervical ripening and labor induction: clinical guidelines. Clinical Obstetrics and Gynecology. 2000;43(3):524-36. 
21. Adair CD. Nonpharmacologic approaches to cervical priming and labor induction. Clinical obstetrics and gynecology. 2000;43(3):447-54.

22. Schifrin BS, Lapidus $M$, Doctor $G$, Leviton A. Contraction stress test for antepartum fetal evaluation. Obstetrics and gynecology. 1975;45(4):433-8.

23. Hayden BL, Simpson J, Ewing DE, Otterson WN. Can the oxytocin challenge test serve as the primary method for managing high-risk pregnancies? Obstetrics and gynecology. 1975;46(3):251-4.

24. Cammu H, Martens G, Ruyssinck G, Amy J-J. Outcome after elective labor induction in nulliparous women: a matched cohort study. American journal of obstetrics and gynecology. 2002;186(2):240-4.

25. Vahratian A, Zhang J, Troendle JF, Sciscione AC, Hoffman MK. Labor progression and risk of cesarean delivery in electively induced nulliparas. Obstetrics \& Gynecology. 2005;105(4):698-704.

26. Evertson LR, Gauthier RJ, Collea JV. Fetal demise following negative contraction stress tests. Obstetrics and Gynecology. 1978;51(6):671-3.

27. Nageotte MP, Towers CV, Asrat T, Freeman RK, Dorchester W. The value of a negative antepartum test: contraction stress test and modified biophysical profile. Obstetrics and gynecology. 1994;84(2):231-4.

\section{Tables}

Table 1: Labour induction methods used in patients with a negative OCT

\begin{tabular}{|lll|}
\hline Labour induction method used & $\mathrm{n}$ & $\%$ \\
\hline No induction & 20 & $4.5 \%$ \\
\hline Labour induction & 427 & $95.5 \%$ \\
\hline Dinoprostone & 237 & $53.0 \%$ \\
\hline Oxytocin & 117 & $26.2 \%$ \\
\hline Cook Balloon + Oxytocin & 47 & $10.5 \%$ \\
\hline Foley Balloon + Oxytocin & 26 & $5.8 \%$ \\
\hline
\end{tabular}

Table 2: Mode of delivery and indications in patients with negative OCT in the induction group 


\begin{tabular}{|llll|}
\hline \multirow{2}{*}{ Mode of delivery } & VD & $\mathrm{n}$ & $\%$ \\
\cline { 2 - 4 } & $\mathrm{C} / \mathrm{S}$ & 310 & $72.6 \%$ \\
\hline & $\mathrm{C} / \mathrm{S}$ indications & & \\
\hline Fetal distress & 39 & $33.3 \%$ \\
\hline Non-progressive labour & 74 & $63.2 \%$ \\
\hline Placental detachment & 2 & $1.7 \%$ \\
\hline Cordon Prolapse & 1 & $0.9 \%$ \\
\hline Development of chorioamnionitis & 1 & $0.9 \%$ \\
\hline
\end{tabular}

Table 3: Fetal distress development following a negative OCT according to risk factors in the induction group 
Risk factor prompting OCT

Fetal distress $(-) \quad$ Total $n=427$

\begin{tabular}{|c|c|c|c|c|}
\hline & Fetal distress $(+)$ & \multirow[t]{2}{*}{$n=388(90,9 \%)$} & & \multirow[t]{2}{*}{$\mathrm{p}$} \\
\hline & $n=39(9,1 \%)$ & & & \\
\hline Oligohydramnios & $10(5 \%)$ & $166(95 \%)$ & 176 & $0.038^{X^{2}}$ \\
\hline Post-term and oligohydramnios & $6(11 \%)$ & $48(89 \%)$ & 54 & $0.589^{X^{2}}$ \\
\hline Post-term & $6(11 \%)$ & $48(89 \%)$ & 54 & $0.589^{x^{2}}$ \\
\hline IUGR and Oligohydramnios & $2(5 \%)$ & $36(95 \%)$ & 38 & $0.386^{X^{2}}$ \\
\hline Decreased fetal movements & $3(8 \%)$ & $33(92 \%)$ & 36 & $0.862^{X^{2}}$ \\
\hline IUGR & $4(12 \%)$ & $27(88 \%)$ & 31 & $0.449^{X^{2}}$ \\
\hline Non-reactive NST & $3(13 \%)$ & $19(87 \%)$ & 22 & $0.452^{\mathrm{X}^{2}}$ \\
\hline Preeclampsia & $3(33 \%)$ & $6(67 \%)$ & 9 & $0.011^{X^{2}}$ \\
\hline Gestational Diabetes Mellitus & $0(0)$ & $3(100 \%)$ & 3 & $0.582^{X^{2}}$ \\
\hline Polyhydramnios & $1(50 \%)$ & $1(50 \%)$ & 2 & $0.044^{X^{2}}$ \\
\hline Gestational cholestasis & $1(50 \%)$ & $1(50 \%)$ & 2 & $0.044^{x^{2}}$ \\
\hline
\end{tabular}

Table 4: Fetal distress development in patients with a negative OCT according to induction methods 


\begin{tabular}{|llll|}
\hline & Fetal distress $(+)$ & Fetal distress (-) & $\mathrm{p}$ \\
\hline & $\mathrm{n}(\%)$ & $\mathrm{n}(\%)$ & \\
\hline No induction & $5(25)$ & $15(75)$ & $0.020^{\mathrm{X}^{2}}$ \\
\hline Labour induction & $39(9.1)$ & $388(90.9)$ & \\
\hline Labour induction method & & & \\
\hline Dinoprostone & $25(10.5)$ & $212(89.5)$ & $0.257^{\mathrm{X}^{2}}$ \\
\hline Oxytocin & $11(9.4)$ & $106(90.6)$ & $0.906^{\mathrm{X}^{2}}$ \\
\hline Cook Balloon + Oxytocin & $1(2.1)$ & $46(97.9)$ & $0.077^{\mathrm{X}^{2}}$ \\
\hline Foley Balloon + Oxytocin & $2(7.7)$ & $24(92.3)$ & $0.792^{\mathrm{X}^{2}}$ \\
\hline & & & \\
\hline
\end{tabular}

Table 5: NICU admission and its indications in newborns of patients with a negative OCT in the induction group

\begin{tabular}{|llll|}
\hline & & \multicolumn{1}{c}{$\mathrm{n}$} & \multicolumn{1}{c|}{$\%$} \\
\hline NICU Admission & No & 397 & $93 \%$ \\
\cline { 2 - 4 } & Yes & 30 & $7 \%$ \\
\hline Indication for NICU admission & & \\
\hline Neonatal respiratory distress & 16 & $53.3 \%$ \\
\hline Neonatal jaundice & 10 & $33.3 \%$ \\
\hline Prematurity & 3 & $10 \%$ \\
\hline Brachial Plexus Injury & 1 & $3.3 \%$ \\
\hline
\end{tabular}

Table 6: Perinatal outcomes according to gestational age in the induction group 
Gestational age $\geq 37-<41$ Gestational age $\geq 41$

$\begin{array}{lll}\mathrm{n}=311 & \mathrm{n}=108 & \mathrm{p} \\ \text { Mean } \pm \mathrm{SD} / \mathrm{n}-\% & \text { Mean } \pm \mathrm{SD} / \mathrm{n}-\%\end{array}$

\begin{tabular}{|c|c|c|c|c|}
\hline \multicolumn{2}{|c|}{ Birth weight (g) } & $3011 \pm 383$ & $3394 \pm 349$ & $<0,001^{t}$ \\
\hline \multirow{2}{*}{\multicolumn{2}{|c|}{ Birth length $(\mathrm{cm})$}} & $49.2 \pm 2.4$ & $51.2 \pm 1.5$ & $<0,001$ \\
\hline & & & & $(\mathrm{t})$ \\
\hline \multirow[t]{2}{*}{ Sex } & Boy & $146(46.9)$ & $49(45.4)$ & \multirow{2}{*}{$0,777^{x^{2}}$} \\
\hline & Girl & $165(53.1)$ & $59(54.6)$ & \\
\hline
\end{tabular}

\begin{tabular}{|llll} 
Apgar score on minute 1 & $8.9 \pm 0.6$ & $8.8 \pm 0.6$ & $0,594^{\mathrm{t}}$ \\
\hline Apgar score on minute 5 & $9.9 \pm 0.5$ & $9.8 \pm 0.5$ & $0,480^{\mathrm{t}}$
\end{tabular}

\section{Perinatal complications}

\begin{tabular}{|c|c|c|c|}
\hline No & $310(99.7)$ & $107(99.1)$ & \multirow[t]{2}{*}{$0,450^{x^{2}}$} \\
\hline Shoulder dystocia & $1(0.3)$ & $1(0.9)$ & \\
\hline Length of hospital stay (days) & $3.0 \pm 1.7$ & $3.8 \pm 2.5$ & $0,449^{t}$ \\
\hline \multicolumn{4}{|l|}{ NICU admission } \\
\hline No & 292(93.9) & $102(94.4)$ & \multirow[t]{2}{*}{$0,391^{x^{2}}$} \\
\hline Yes & $19(6.1)$ & $6(5.6)$ & \\
\hline
\end{tabular}

\section{Cause of NICU admission}

\begin{tabular}{lll}
\hline Neonatal jaundice & $7(36.8)$ & $3(50.0)$ \\
\hline Neonatal respiratory distress & $11(57.9)$ & $3(50.0)$ \\
\hline Brachial plexus injury & $1(5.3)$ & $0(0.0)$ \\
\hline Prematurity & $0(0.0)$ & $0(0.0)$
\end{tabular}
$\mathrm{X}^{2}$ Chi-square test
t Student T test 
Table 7: Relationship between time from OCT to delivery, fetal distress and Apgar score at minute 5 in the induction group

\begin{tabular}{|c|c|c|c|c|c|c|}
\hline $\begin{array}{l}\text { Time from OCT to } \\
\text { delivery }\end{array}$ & $\begin{array}{l}\text { Fetal } \\
\text { distress } \\
(-)\end{array}$ & $\begin{array}{l}\text { Fetal } \\
\text { distress } \\
(+)\end{array}$ & $p$ & $\begin{array}{l}\text { APGAR } \\
\geq 7\end{array}$ & $\begin{array}{l}\text { APGAR } \\
<7\end{array}$ & p \\
\hline & n (\%) & n (\%) & & $\mathrm{n}(\%)$ & $\mathrm{n}(\%)$ & \\
\hline $0-24$ hours & 208 (89.6) & $24(10.4)$ & \multirow{3}{*}{$0.388^{X^{2}}$} & $\begin{array}{l}231 \\
(99.6)\end{array}$ & $1(0.4)$ & \multirow{3}{*}{$0.416^{\mathrm{X}^{2}}$} \\
\hline $24-72$ hours & 167 (91.8) & $15(8.2)$ & & $\begin{array}{l}179 \\
(98.4)\end{array}$ & $3(1.6)$ & \\
\hline$>72$ hours & 13 (100) & $0(0.0)$ & & 13 (100) & $0(0.0)$ & \\
\hline
\end{tabular}

$\mathrm{X}^{2}$ Chi-square test 